\title{
PENILAIAN RANCANGAN KEMASAN BAKPIA BERBENTUK RANTANG MENGGUNAKAN METODE QUALITY FUNCTION DEPLOYMENT (QFD)
}

\author{
Ika Atsari Dewi ${ }^{12} *$ Cahyo Wibowo ${ }^{1}$, Sucipto Sucipto ${ }^{1,3}$ \\ ${ }^{1}$ Jurusan Teknologi Industri Pertanian Universitas Brawijaya \\ ${ }^{2}$ Kelompok Kajian Agroindustri Palma Universitas Brawijaya \\ ${ }^{3}$ Halal Qualified Industry Development (Hal-Q ID) Universitas Brwaijaya \\ Jl. Veteran Malang 65145 \\ *Email: ikaatsaridewi@ub.ac.id
}

\begin{abstract}
Bakpia is one food product that uses duplex cardboard as packaging material. Buying bakpia both in a small or big amount of packages need secondary packaging such as plastic bags and cardboards. "Rantang"-shaped packaging is designed to get practical, enviromental friendly, and attractive packaging. The objective of this research is to find out the importance level of customer attribute (Whats) against "rantang"-shaped packaging and to find out the technical responses that must be carried out by a manufacturer in order the packaging design is accepted by consumers. QFD method is used to find out consumers' needs and desires as well as to systematically evaluate packaging capabilities sampled from 30 respondents. QFD method comprises of 7 phases, namely, collecting consumer voice, organizing House of Quality $(H o Q)$, creating technical response, determining the technical response relationship to consumer needs, determining technical relations, benchmarking, and target. Results show the highest scores for importance level of consumer attribute go to packaging shape and packaging design with Importance to customer score of 4,67 dan 4,43 which are above average. Manufacturers should pay more attention to visual packaging design, packaging convenience while carrying, practical, varius number of stack, maximum limit of stack, appropriate cardboard, and precise packaging size as technical responses.
\end{abstract}

Keyword: Bakpia, Packaging design, Quality Function Deployment (QFD).

\section{PENDAHULUAN}

Penjualan produk di pasar dipengaruhi beberapa hal, salah satunya kemasan. Menurut Sofian (2011), desain kemasan produk menciptakan daya ingat pada konsumen. Kesadaran merek produk akan tertanam dalam benak konsumen selamanya. Bakpia merupakan salah satu jajanan yang digemari wisatawan sebagai oleh-oleh. Bentuk kemasan bakpia selama ini sangat sederhana. Penambahan kemasan sekunder berupa kantong plastik juga kurang efisien dan berdampak buruk bagi lingkungan. Bentuk kemasan bakpia yang sederhana juga bisa mempengaruhi minat beli konsumen. Saat ini kemasan sudah berfungsi sebagai media komunikasi. Kemasan yang menarik menambah minat beli konsumen (Lestari, 2013). Untuk mengatasi masalah tersebut dibutuhkan desain kemasan bakpia yang ramah lingkungan, praktis, dan menarik sehingga dapat menambah minat beli konsumen. Salah satu desain kemasan yang tepat untuk mengatasi masalah tersebut ialah desain kemasan bakpia berbentuk rantang. Perancangan desain 
kemasan bakpia yang menarik dan berkarakter dapat membuat produk bakpia mempunyai ciri khast yang mempengaruhi ketertarikan konsumen untuk membeli. Dengan kata lain kemasan juga dapat menjual produk yang dikemasnya (Endang, 2013).

Metode QFD digunakan mengetahui kebutuhan dan keinginan konsumen. Metode QFD terdiri dari 7 fase, yaitu fase pengumpulan suara konsumen, penyusunan House of Quality (HoQ), pembuatan respon teknis, menentukan hubungan respon teknis dengan kebutuhan konsumen, menentukan hubungan teknis, benchmarking, dan target. QFD telah digunakan untuk melakukan perbaikan kemasan dan proses sebagai berikut, desain kemasan sekunder untuk transportasi jarak jauh telur ayam ras (Violetasari et al., 2016) dan peningkatan kualitas produk yoghurt (Sucipto et al., 2017). Rancangan kemasan bakpia berbentuk rantang pada penelitian ini dinilai dengan Quality Function Deployment (QFD).

Penelitian bertujuan mengetahui atribut tingkat kepentingan konsumen (Whats) terhadap kemasan bakpia berbentuk rantang dan respon teknis yang perlu dilakukan produsen agar kemasan bakpia berbentuk rantang diterima konsumen.

\section{METODE}

Penelitian ini dilaksanakan di Jurusan Teknologi Industri Pertanian, Universitas Brawijaya, Kota Malang. Pengambilan data dilakukan di Kota Batu dan pengolahan data di Laboratorium Komputasi dan Analisis Sistem, Jurusan Teknologi Industri Pertanian, Fakultas Teknologi Pertanian, Universitas Brawijaya.

Penelitian dilakukan dengan langkahlangkah pada Gambar 1. Desain kemasan bakpia berbentuk rantang berbahan dasar karton dupleks dengan gramatur kertas $250 \mathrm{~g}$. Isi bakpia masing-masing tumpukan 20-30 bakpia dengan bobot 250 gram. Dimensi kemasan panjang $15 \mathrm{~cm}$, lebar 10 $\mathrm{cm}$, dan tinggi $4 \mathrm{~cm}$ pada masing-masing bagian kemasan rantang. Bagian atas kemasan rantang terdapat pegangan untuk mempermudah membawa kemasan. Gambar kerangka dan model desain kemasan bakpia berbentuk rantang dapat dilihat pada Gambar 2.

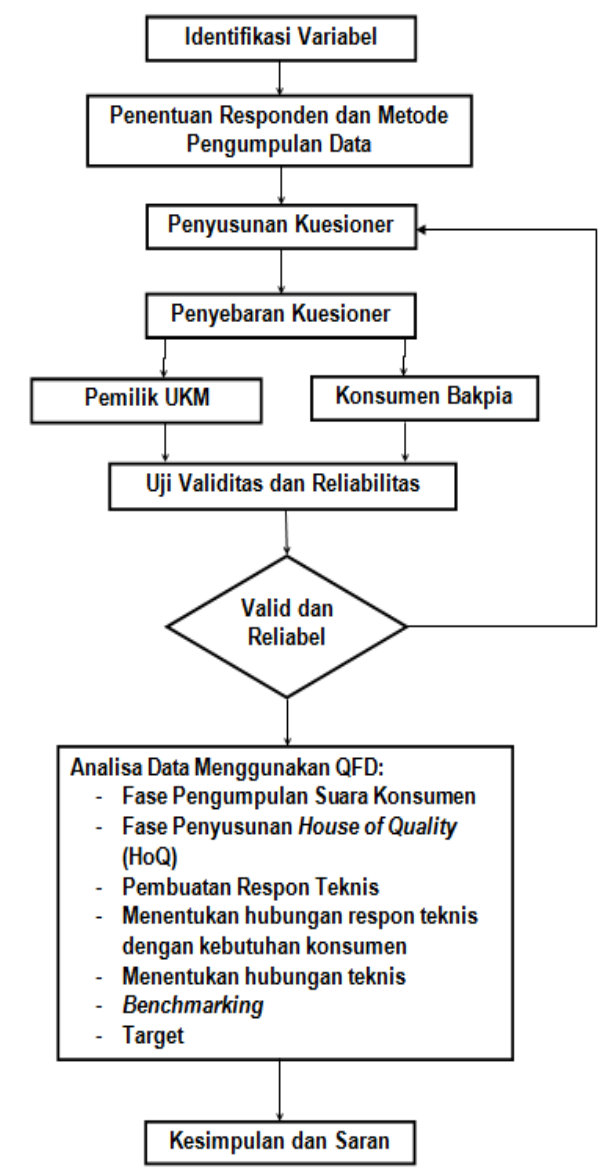

Gambar 1 Prosedur penelitian

Metode QFD pada penelitian ini menggunakan responden 30 orang yang menilai desain kemasan bakpia. Kuesioner penelitian ini menggunakan model pertanyaan tertutup dengan skala Likert pada konsumen dan model pertanyaan terbuka ke salah satu produsen bakpia. Kuesioner ini disusun setelah mengetahui harapan pelanggan (whats). Kuesioner 
yang digunakan adalah kuesioner prioritas dan kuesioner evaluasi pelanggan untuk mengetahui tingkat kepentingan pelanggan terhadap model kemasan desain baru bakpia berbentuk rantang.

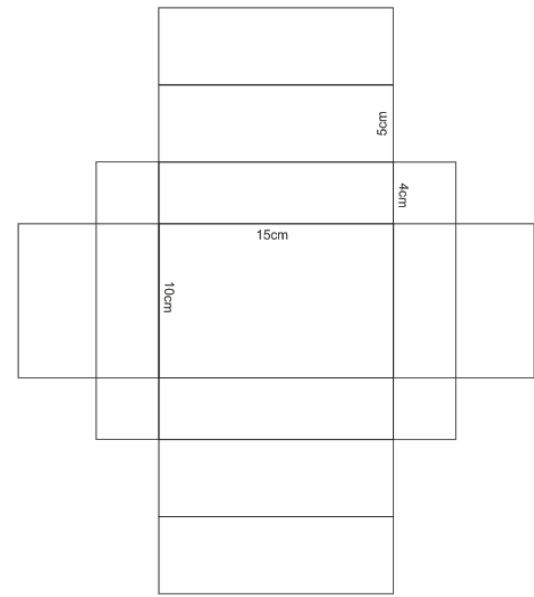

Bagian kepala

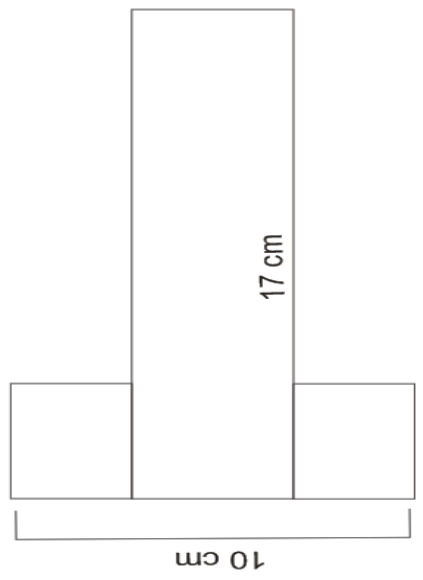

Bagian tali

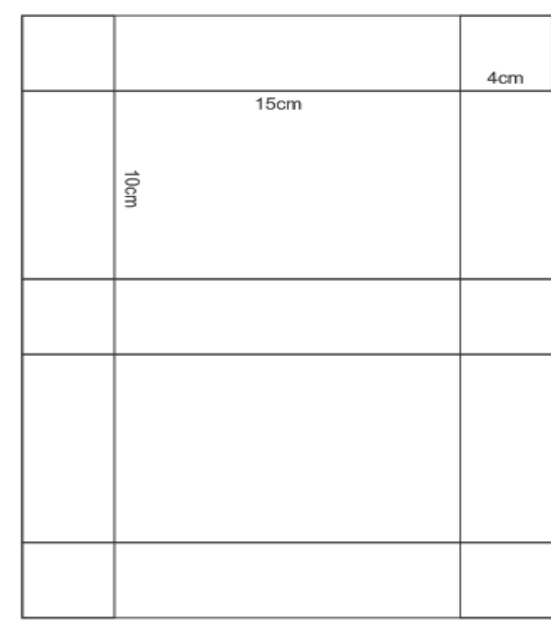

Bagian tubuh

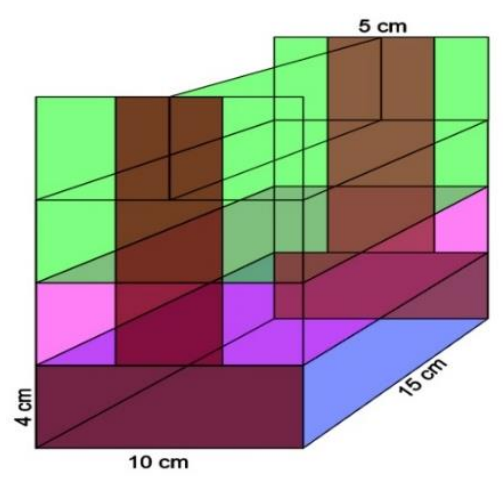

Model rancangan

Gambar 2 Kerangka kemasan bakpia berbentuk rantang

\section{HASIL DAN PEMBAHASAN} Analisa QFD

\section{Pengumpulan Suara Konsumen}

Fase pengumpulan suara konsumen untuk menentukan atribut tingkat kepentingan konsumen (Whats) dan mengukur tingkat kepentingan tersebut. Penilaian tingkat kepentingan yang diberikan oleh konsumen dengan skala 1-
5. Bila atribut tingkat kepentingan di atas $50 \%$, maka atribut tersebut dianggap penting. Dari pengukuran tingkat kepentingan konsmen didapat 6 atribut antara lain: desain kemasan, kekuatan kemasan, dimensi kemasan, bentuk kemasan, kapasitas kemasan dan ketahanan kemasan. Prototipe desain kemasan bentuk rantang pada Gambar 3 . 


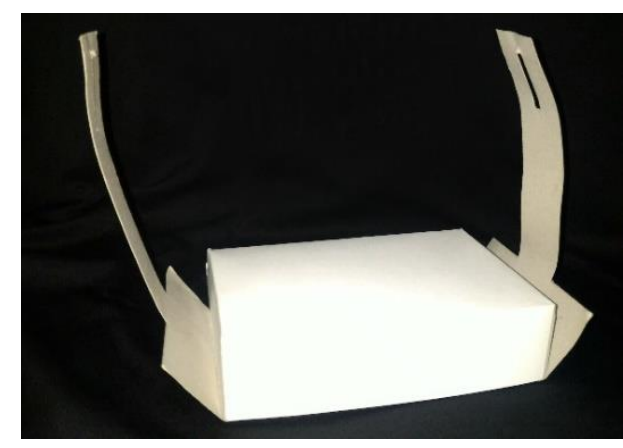

Kotak bagian bawah

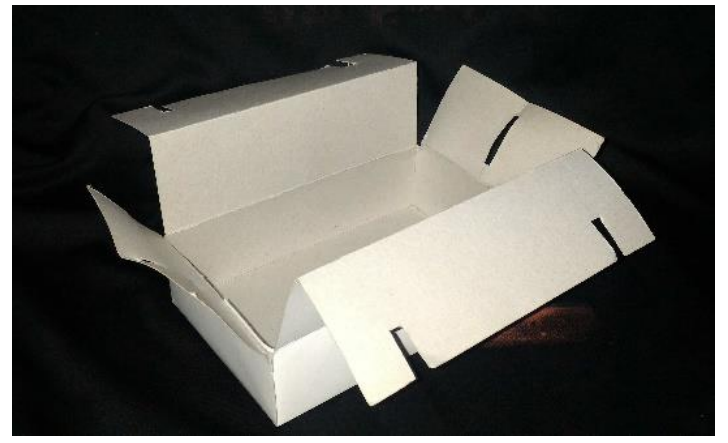

Kotak bagian atas

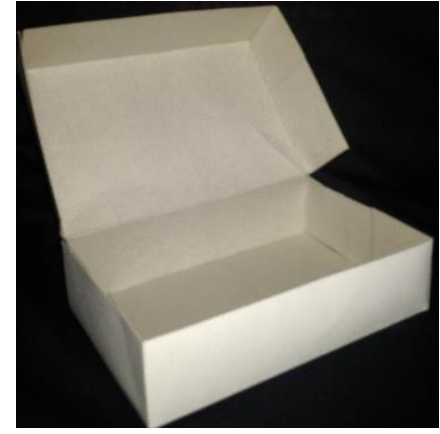

Kotak bagian tengah

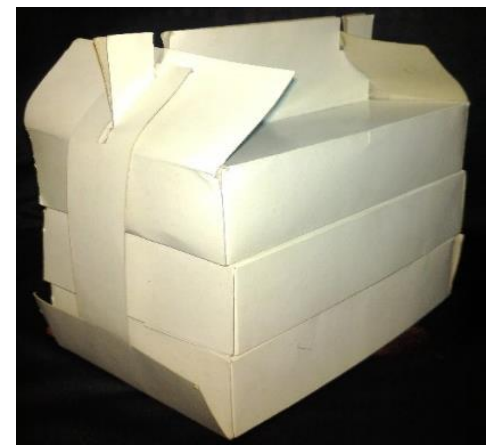

Kemasan setelah dirangkai

Gambar 1 Prototipe Desain Kemasan Bakpia Berbentuk Rantang

2. Penyusunan House of Quality (HoQ)

Penyusunan House of Quality (HoQ) dilakukan bertahap. Pertama pembuatan matriks kebutuhan. Selanjutnya pembuatan importance to customer, customer satisfaction, goal, improvement ratio, row weight dan normalized row weight.

\section{Importance to customer (ITC)}

Hasil perhitungan terlihat nilai ITC setiap atribut pada Tabel 1.

Tabel 1 Nilai ITC

\begin{tabular}{llc}
\hline No & Atribut & $\begin{array}{c}\text { Importance to } \\
\text { custumer }\end{array}$ \\
\hline 1 & Desain kemasan & 4,43 \\
2 & Kekuatan kemasan & 3,90 \\
3 & Dimensi kemasan & 4,03 \\
4 & Bentuk kemasan & 4,67 \\
5 & Kapasitas kemasan & 3,77 \\
6 & Ketahanan kemasan & 4,10 \\
\hline & Rata-rata & 4,15 \\
\hline
\end{tabular}

Bentuk kemasan baru bakpia menjadi poin paling penting. Posisi kedua atribut desain kemasan bakpia berbentuk rantang dianggap penting oleh konsumen. Tingkat kepentingan atribut (importance to customer) adalah nilai yang menunjukkan seberapa penting atribut menentukan kualitas produk (Wirya, 2008).

\section{Custumer Satisfaction Performance dan} Goal

Customer satisfaction performance (CSP) merupakan penilaian persepsi konsumen mengenai seberapa baik kemasan bakpia sekarang dapat memenuhi kebutuhan pelanggan. Goal merupakan nilai CSP paling tinggi antara kemasan bakpia selama ini dan kemasan bakpia berbentuk rantang. Nilai CSP dan goal pada Tabel 2. 
Tabel 2 Nilai customer satisfaction performance dan goal

\begin{tabular}{lllll}
\hline No & Atribut & Kemasan lama & Kemasan baru & Goal \\
\hline 1 & Desain kemasan & 2,7 & $\mathbf{4 , 3}$ & 4,3 \\
2 & Kekuatan kemasan & 3,17 & $\mathbf{3 , 5}$ & 3,5 \\
3 & Dimensi kemasan & $\mathbf{3 , 8 3}$ & 3,43 & 3,83 \\
4 & Bentuk kemasan & 3,07 & $\mathbf{3 , 7 3}$ & 3,73 \\
5 & Kapasitas kemasan & 3,1 & $\mathbf{3 , 5 7}$ & 3,57 \\
6 & Ketahanan kemasan & $\mathbf{3 , 7 3}$ & 3,53 & 3,73 \\
\hline
\end{tabular}

Tabel 3 Nilai improvement ratio

\begin{tabular}{lllll}
\hline No & Atribut & Kemasan lama & Goal & Improvement Ratio \\
\hline 1 & Desain kemasan & 2,7 & 4,3 & 1,59 \\
2 & Kekuatan kemasan & 3,17 & 3,5 & 1,11 \\
3 & Dimensi kemasan & 3,83 & 3,83 & 1 \\
4 & Bentuk kemasan & 3,07 & 3,73 & 1,22 \\
5 & Kapasitas kemasan & 3,1 & 3,57 & 1,15 \\
6 & Ketahanan kemasan & 3,73 & 3,73 & 1 \\
\hline
\end{tabular}

Hasil CSP menunjukkan persepsi konsumen mengenai kemasan bakpia selama ini dan kemasan bakpia berbentuk rantang. Kemasan bakpia berbentuk rantang terlihat lebih unggul di 4 atribut yaitu desain kemasan, kekuatan kemasan, bentuk kemasan dan kapasitas kemasan. Menurut Siswiyanti (2014), kemasan suatu produk juga merupakan penentu dalam mencapai kepuasan konsumen. Kemasan produk selain merupakan daya tarik bagi konsumen untuk membeli, juga merupakan penentu konsumen melakukan pembelian, sebab dengan bentuk kemasan, konsumen dapat mengenal isi produk.

\section{Improvement Ratio (IR)}

Improvement Ratio adalah salah satu dari Importance to Customer yang paling penting, dengan begitu menentukan Goal adalah langkah strategi yang krusial dalam QFD. Menurut Muharam (2011), Pencapaian Goal secara normal dinyatakan di dalam nilai skala kuantitatif yang sama sebagai suatu tingkat pencapaian. Goal digunakan untuk menghitung Improvement Ratio. Nilai improvement ratio dapat dilihat pada Tabel 3. Nilai IR diketahui atribut kemasan bakpia yang selama ini ada perlu diperbaiki desain kemasan, kekuatan kemasan, bentuk kemasan dan kapasitas kemasannya.

\section{Sales Point}

Sales point merupakan deskripsi pengaruh perubahan atribut kepentingan konsumen terhadap tingkat kepuasan konsumen. Skala yang digunakan adalah 1; 1,2 dan 1,5 dengan ketentuan makin besar skala yang digunakan makin besar pula pengaruh yang diberikan atribut kepentingan konsumen terhadap tingkat kepuasan konsumen (Erfando,2007). Nilai sales point tertinggi berada pada atribut bentuk kemasan dan tertinggi kedua berada pada atribut desain kemasan. Nilai sales point dari masing-masing atribut dapat dilihat pada Tabel 4. 
Tabel 4 Nilai sales point

\begin{tabular}{llccc}
\hline No. & \multicolumn{1}{c}{ Atribut } & $\begin{array}{c}\text { Importance to } \\
\text { customer }\end{array}$ & $\begin{array}{c}\text { Urutan } \\
\text { kepentingan }\end{array}$ & Sales point \\
\hline 1 & Desain kemasan & 4,43 & 2 & 1,2 \\
2 & Kekuatan kemasan & 3,9 & 5 & 1 \\
3 & Dimensi kemasan & 4,03 & 4 & 1 \\
4 & Bentuk kemasan & 4,67 & 1 & 1,5 \\
5 & Kapasitas kemasan & 3,77 & 6 & 1 \\
6 & Ketahanan & 4,1 & 3 & 1 \\
\hline
\end{tabular}

Tabel 5 Nilai row weight dan normalized row weight

\begin{tabular}{lcc}
\hline Atribut & Row weight & Normalized row weight \\
\hline Desain kemasan & 8.45 & 0.25 \\
Kekuatan kemasan & 4.33 & 0.12811 \\
Dimensi kemasan & 4.03 & 0.11923 \\
Bentuk kemasan & $\mathbf{8 . 5 5}$ & $\mathbf{0 . 2 5 2 9 6}$ \\
Kapasitas kemasan & 4.34 & 0.1284 \\
Ketahanan kemasan & 4.1 & 0.1213 \\
\hline
\end{tabular}

Row Weight dan Normalized Row Weight

Row weight merupakan nilai bobot atribut penilaian konsumen terhadap matriks perencanaan. Normalize row weight (NRW) digunakan untuk menghitung row weight dalam bentuk presentase. Perhitungan normalitas bobot setiap atribut untuk memudahkan penentuan prioritas pengembangan. Semakin besar nilai row weight suatu atribut maka semakin tinggi prioritas pengembangannya (Wicaksono, 2013). Data nilai Row Weight dan Normalized Row Weight dapat dilihat pada Tabel 5.

Nilai row weight tertinggi adalah atribut bentuk kemasan dengan nilai 8,55. Nilai normalized row weight tertinggi juga terdapat pada atribut bentuk kemasan dengan nilai 0,25296. Hal ini menunjukkan bahwa atribut bentuk kemasan menjadi prioritas utama dalam perancangan desain kemasan bakpia baru yaitu bentuk kemasan bakpia yang ergonomis.

\section{Pembuatan respon teknis}

Respon teknis penelitian ini merupakan hasil wawancara dengan UKM. Respon teknis merupakan transformasi dari kebutuhan atau keinginan pelanggan. Respon teknis UKM pada Tabel 6 .

Respon teknis (Hows) membentuk strategi usaha untuk merealisasikan atribut whats. Pada hows, sebuah usaha dapat mengukur dan mengontrol kualitas untuk memastikan bahwa atribut whats telah memberikan kepuasan (Sudarwanto, 2010). 
Tabel 6 Respon teknis

\begin{tabular}{lll}
\hline No & Atribut & Respon Teknis \\
\hline 1 & Desain kemasan & Desain kemasan praktis, desain visual kemasan \\
2 & Kekuatan kemasan & Jenis karton sesuai \\
3 & Dimensi kemasan & Ukuran kemasan tepat \\
4 & Bentuk kemasan & Kemasan nyaman saat dibawa \\
5 & Kapasitas kemasan & jumlah tumpukan kemasan bervariasi \\
6 & Ketahanan kemasan & Berat produk tepat, batas maksimal tumpukan \\
\hline
\end{tabular}

4. Penentuan Hubungan Atribut Hows dengan Atribut Whats

Hubungan atribut what dan hows merupakan penilaian korelasi antar elemen dari atribut tingkat kepentingan konsumen dan respon teknis yang dirumuskan pada atribut hows dapat dilihat pada Gambar 4.

a. Hubungan atribut Hows-Whats $(1,1)$; $(1,2) ;(1,5)$

Atribut desain kemasan memiliki hubungan sedang dengan respon teknis membuat desain kemasan praktis. Atribut desain kemasan juga memiliki hubungan kuat dengan respon teknis desain visual kemasan dan hubungan lemah dengan respon teknis kemasan nyaman saat dibawa.

\section{b. Hubungan atribut Hows-Whats $(2,3)$}

Atribut kekuatan kemasan hanya memiliki satu hubungan dengan respon teknis yaitu hubungan kuat dengan respon teknis jenis karton sesuai. Hal ini karena untuk memenuhi keinginan konsumen terhadap kemasan berbentuk rantang yang kuat perlu pemilihan baku kemasan karton dupleks dengan gramatur tebal agar kuat menahan beban berat produk.

c. Hubungan Atribut Hows-Whats $(3,1)$; $(3,2) ;(3,4) ;(3,5)$

Atribut dimensi kemasan memiliki 4 hubungan dengan respon teknis. Pertama, atribut dimensi kemasan memiliki hubungan sedang dengan respon teknis desain kemasan praktis. Kedua, dimensi kemasan memlki hubungan lemah dengan respon teknis desain visual kemasan. Ketiga, memiliki hubungan kuat dengan respon teknis ukuran kemasan tepat dan terakhir memiliki hubungan lemah dengan respon teknis merancang kemasan nyaman saat dibawa.

d. Hubungan atribut Hows-Whats (4,1); $(4,2) ;(4,3) ;(4,4) ;(4,5) ;(4,8)$

Pada atribut bentuk kemasan memiliki hubungan lemah dengan respon teknis desain visual kemasan dan respon teknis batas maksimal tumpukan. Hubungan sedang pada atribut bentuk kemasan juga terlihat dengan respon teknis jenis karton sesuai dan respon teknis ukuran kemasan tepat. Selain itu, atribut bentuk kemasan juga memiliki hubungan kuat dengan respon teknis membuat desain kemasan yang praktis dan respon teknis kemasan nyaman saat dibawa.

e. Hubungan atribut Hows-Whats $(5,1)$;
$(5,4) ;(5,6) ;(5,7) ;(5,8)$

Atribut kapasitas kemasan memiliki hubungan sedang dengan respon teknis desain kemasan praktis, ukuran kemasan tepat dan batas maksimal tumpukan. Selain itu, atribut kapasitas kemasan juga memiliki hubungan lemah dan kuat masing-masing dengan respon teknis berat produk tepat dan jumlah tumpukan kemasan bervariasi. 
f. Hubungan atribut Hows-Whats (6,3); $(6,6) ;(6,7) ;(6.8)$

Pada atribut ketahanan kemasan memilki hubungan kuat dengan 3 respon teknis yaitu jenis karton sesuai, berat produk tepat dan batas maksimal tumpukan. Atribut ketahanan kemasan juga memiliki hubungan sedang dengan respon teknis jumlah tumpukan kemasan bervariasi.

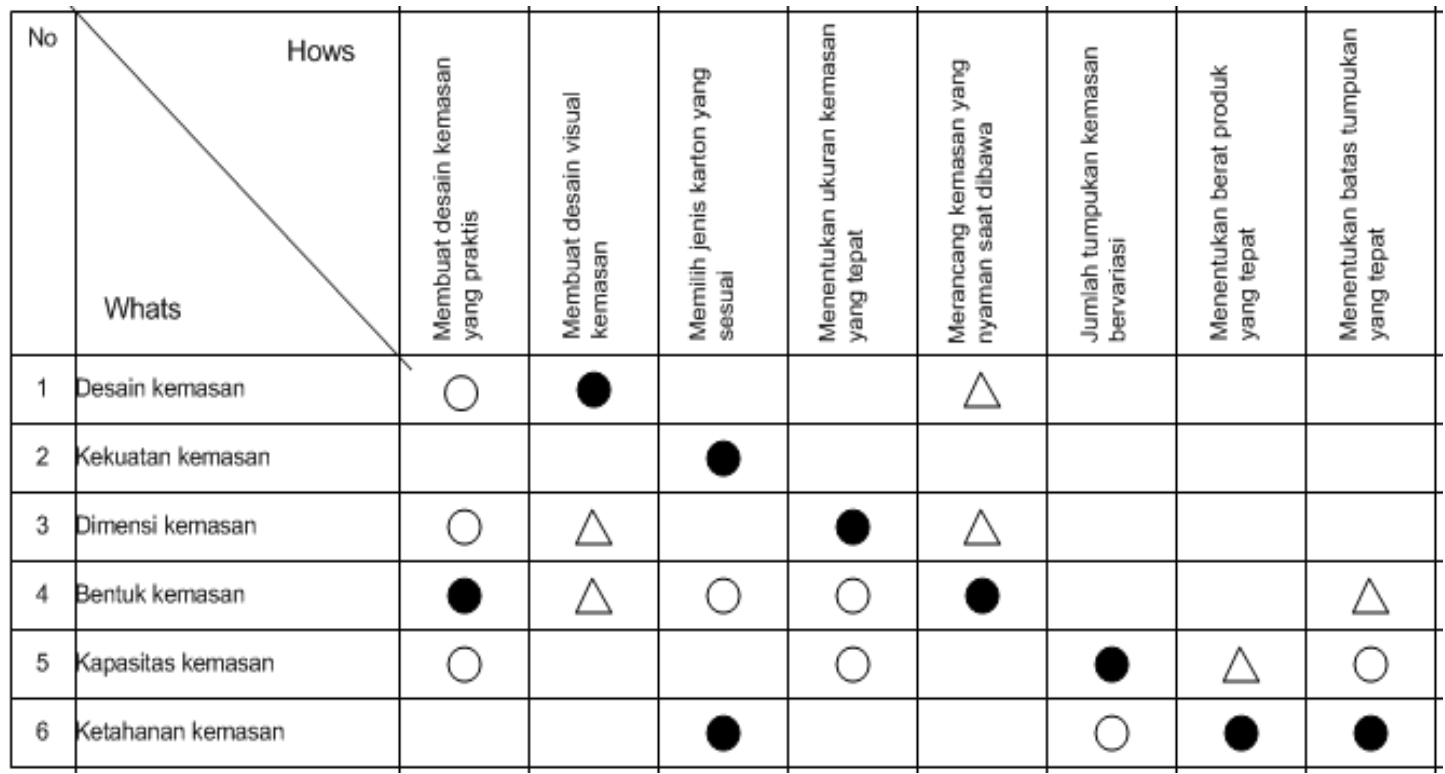

Gambar 2 Hubungan atribut Whats dan Hows

\section{Hubungan antar atribut Hows}

Respon teknis (Hows) memiliki hubungan antar masing-masing atributnya. Gambar hubungan antar atribut Hows dapat dilihat pada Gambar 5.

Hubungan antar atributs hows juga harus ditentukan. Hal ini untuk mengetahui apakah suatu proses dalam atributs hows saling menguntungkan (positif) atau merugikan (negatif). Namun, tidak semua atribut hows memilki hubungan dengan atribut yang lain atau bahkan salah satu atribut hows memliki hubungan lebih dari satu dengan atribut hows lainnya.

Penjelasan mengenai hubungan antar atribut hows sebagai berikut:

a. Hubungan atribut desain kemasan praktis memiliki hubungan positif lemah dengan atribut ukuran kemasan sesuai, berat produk tepat dan batas maksimal tumpukan. Hubungan positif kuat juga terlihat pada hubungan atribut ini dengan atribut desain visual kemasan dan kemasan nyaman saat dibawa.

b. Atribut hows desain visual kemasan memliki masing-masing satu hubungan positif lemah dan positif kuat secara berurutan pada atribut kemasan nyaman saat dibawa dan ukuran kemasan tepat.

c. Atribut jenis karton sesuai memiliki hubungan positif lemah pada tiga atribut hows lainnya yaitu atribut ukuran kemasan tepat, kemasan nyaman saat dibawa dan berat produk tepat.

d. Atribut ukuran kemasan tepat memiliki hubungan positif kuat dengan atribut kemasan nyaman saat dibawa. Hubungan positif kuat atribut ukuran kemasan tepat juga ada 
dengan atribut batas maksimal tumpukan.

e. Atribut kemasan nyaman saat dibawa memliki hubungan positif lemah dengan atribut jumlah tumpukan kemasan bervariasi. Hubungan positif lemah atribut kemasan nyaman saat dibawa juga ada dengan atribut batas maksimal tumpukan. f. Atribut jumlah tumpukan kemasan bervariasi memiliki hubungan positif kuat pada dua atribut lainnya yaitu pada atribut berat produk tepat dan batas maksimal tumpukan.

g. Pada atribut berat produk tepat memilki hubungan positif lemah dengan atribut batas maksimal tumpukan

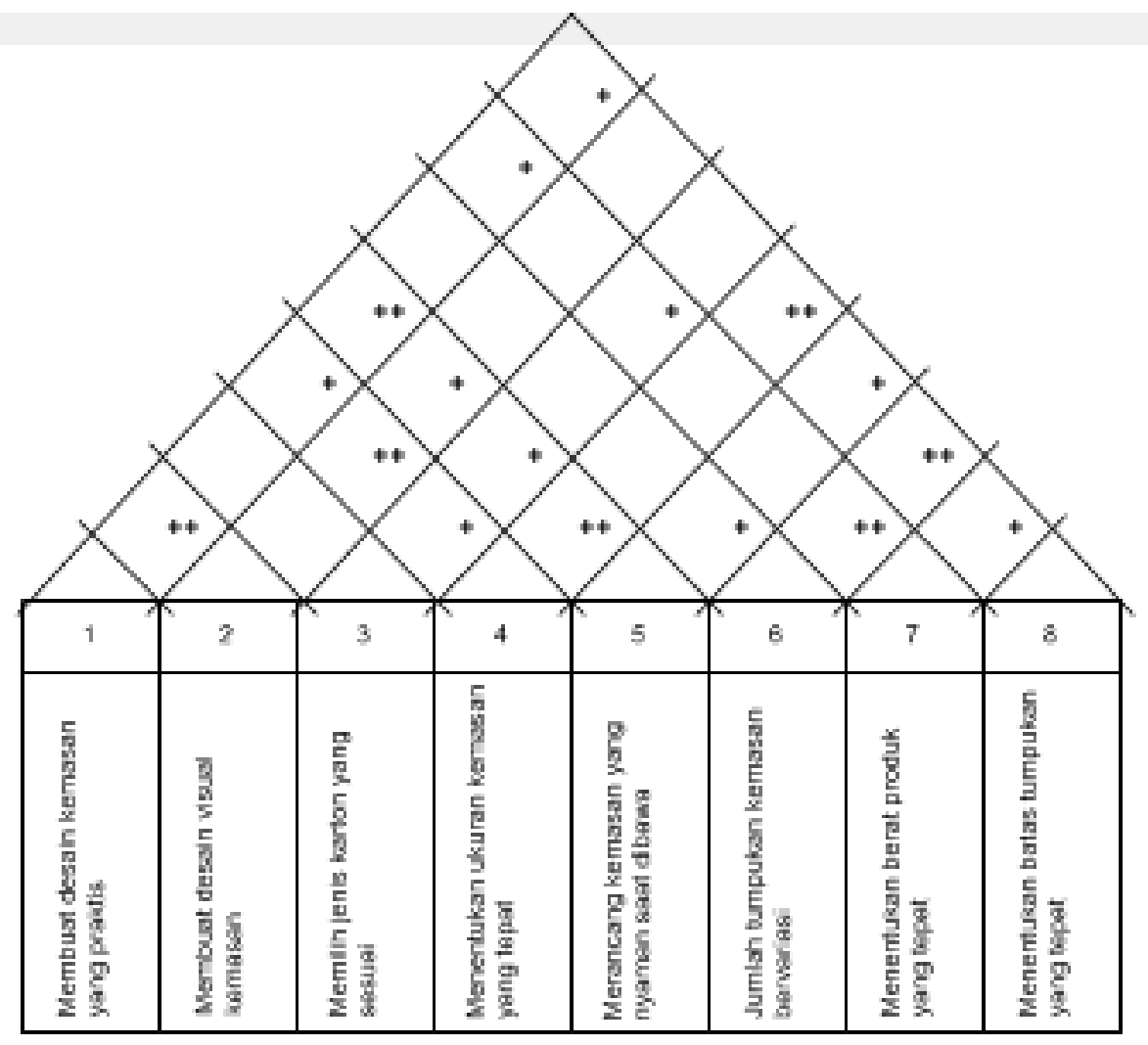

Gambar 3 Hubungan antar atribut Hows

Tabel 7 Prioritas

\begin{tabular}{lllc}
\hline No & Atribut & Bobot respon teknis & Prioritas \\
\hline 1 & Desain kemasan yang praktis & $\mathbf{1 2 7 , 4 1}$ & $\mathbf{1}$ \\
2 & Desain kemasan visual & 88,63 & 4 \\
3 & Jenis karton yang sesuai & $\mathbf{1 0 1 , 5 2}$ & $\mathbf{2}$ \\
4 & Ukuran kemasan yang tepat & 79,94 & 5 \\
5 & Kemasan yang nyaman saat dibawa & $\mathbf{8 9 , 5 3}$ & $\mathbf{3}$ \\
6 & Jumlah tumpukan kemasan yang bervariasi & 51,36 & 6 \\
7 & Berat produk yang tepat & 41,24 & 7 \\
8 & Batas maksimal tumpukan & 25,67 & 8 \\
\hline
\end{tabular}




\section{Prioritas}

Prioritas ini bertujuan mengetahui atribut yang diutamakan. Menurut Cenadi (2007), pelayanan yang elektif harus sesuai urutan prioritas respon teknis. Prioritas diurutkan mulai dari nilai bobot teknis paling tinggi sampai paling rendah. Nilai bobot respon teknis berasal dari nilai masing-masing korelasi teknis dikalikan dengan nilai row wight. Nilai prioritas respon teknis dapat dilihat pada Tabel 7.

Prioritas respon teknis tertinggi ketiga adalah atribut kemasan nyaman dibawa dengan bobot 89,53. Hal ini menunjukkan bahwa kemasan yang nyaman saat dibawa berpengaruh terhadap minat beli konsumen terhadap bakpia. Kemasan berbentuk rantang lebih memudahkan konsumen membawa bakpia walau berjumlah banyak.

7. Benchmarking dan Target
Benchmarking merupakan suatu nilai yang didapat dari perhitungan untuk mengetahui nilai kinerja yang harus dilakukan perusahaan untuk memenuhi kebutuhan konsumen terhadap kemasan bakpia berbentuk rantang. Target merupakan nilai bencmarking tertinggi antara kemasan bakpia selama ini dan kemasan bakpia berbentuk rantang. Kemudian dari nilai target tersebut dapat diketahui respon teknis mana sajakah yang harus dilakukan oleh perusahan untuk memenuhi kebutuhan konsumen terhadap kemasan bakpia. Terdapat satu atribut dari kemasan lama yang nilai benchmarkingnya lebih tinggi dari kemasan baru yaitu berat produk yang tepat dengan nilai 3,67. Benchmarking merupakan suatu proses pengukuran kinerja dengan cara membandingkan dengan kinerja perusahaan yang lebih baik (Suradi, 2006). Nilai benchmarking dan target (Tabel 8).

Tabel 8 Nilai benchmarking dan target

\begin{tabular}{lllll}
\hline No & Atribut & Kemasan Lama & Kemasan baru & Target \\
\hline 1 & Desain kemasan yang praktis & 3,14 & 3,72 & 3,72 \\
2 & Desain visual kemasan & 2,84 & 4,17 & 4,17 \\
3 & Jenis karton yang sesuai & 3,39 & 3,54 & 3,54 \\
4 & Ukuran kemasan yang tepat & 3,5 & 3,52 & 3,52 \\
5 & $\begin{array}{l}\text { Kemasan yang nyaman saat } \\
\text { dibawa }\end{array}$ & 3,11 & 3,75 & 3,75 \\
6 & Jumlah tumpukan kemasan yang & 3,26 & 3,56 & 3,56 \\
& bervariasi & & & \\
7 & Berat produk yang tepat & 3,67 & 3,53 & 3,67 \\
8 & Batas maksimal tumpukan & 3,53 & 3,56 & 3,56 \\
\hline
\end{tabular}

\section{KESIMPULAN}

Berdasar penelitian didapat kesimpulan sebagai berikut:

1. Atribut tingkat kepentingan konsumen (whats) yang paling tinggi untuk memenuhi kebutuhan konsumen terhadap kemasan bakpia berbentuk rantang adalah bentuk kemasan dan desain kemasan dengan nilai Importance to customer 4,67 dan 4,43 yang berada diatas nilai rata-rata.
2. Respon teknis yang harus dilakukan dan diperhatikan oleh produsen agar kemasan bakpia berbentuk rantang dapat diterima oleh konsumen yaitu desain kemasan visual, kemasan nyaman saat dibawa, desain kemasan praktis, jumlah tumpukan kemasan bervariasi, batas maksimal tumpukan, jenis karton sesuai, dan ukuran kemasan tepat dengan nilai bencmarking berturut-turut 4,17; 3,$75 ; 3,72 ; 3,56 ; 3,56 ; 3,54 ; 3,52$. 
DAFTAR PUSTAKA

Cenadi, 2007. Elemen Dalam Desain Komunikasi Visual. Jurnal Universitas Kristen Petra Surabaya 1(1):27-28

Endang, K. 2013. Persepsi Desainer Dan Target Audience Terhadap Desain Kemasan Bakpia Djogdja Ditinjau Dari Aspek Daya Tarik Dan Kriteria Desain. Skripsi Desain Komunikasi Visual. Institut Seni Indonesia Yogyakarta

Erfando, T. 2011. Perancangan Desain Kemasan Transportasi Buah Salak Untuk Kebutuhan Ekspor Dengan Metode Quality Function Deploypment. Skripsi Fakultas Teknik. Universitas Indonesia. Jakarta

Lestari, D.A.S. 2013. Redesain Kemasan Produk Makanan Ringan "Aneka Gorengan Super 2R".Jurnal Desain Komunikasi Visual 17(5): 37-40

Muharam, A.S. 2011. Analisa Pengaruh Desain Kemasan Produk dan Daya Tarik Iklan Terhadap Brand Awareness dan Dampaknya Pada Minat Beli Konsumen. Jurnal Manajemen Ekonomi 1(13): 56-61

Siswiyanti, S,L. 2014. Implementasi Quality Function Deployment (QFD) Dalam Perancangan Produk Alat Penetas Telur Rak Putar. Skripsi Universitas Pancasakti. Tegal

Sofian, S. 2011. Analisis Pengaruh Desain Kemasan Produk Dan Daya Tarik Iklan Terhadap Brand Awareness Dan Dampaknya Pada Minat Beli
Konsumen. Skripsi Universitas Diponegoro. Semarang

Sucipto, S, Prananda, N.A., dan Ikasari, D.M. 2017. Application of QFD Method to Know Priority Attributes to Improve Product Quality of Youghurt Case Study in Cooperative Agro Niaga (KAN) Jabung Malang Regency. Proceedingpaper of International Conference on SocioPolitical Entrepreneurship. 413-427

Sudarwanto, T. 2010. Pengaruh Citra

Merek Dan Desain Kemasan Terhadap Minat Beli Konsumen Pada Produk Susu Ultra. Skripsi Universitas Negeri Surabaya. Surabaya

Suradi, K. 2005. Pengemasan Bahan Pangan Hasil Ternak Dan Penentuan Waktu Kadaluarsa. Jurnal Fasilitas Penanganan Pengemasan 1(2): 5860

Violetasari, P.I., Hidayat, N., dan Sucipto. 2016. Perancangan Kemasan Sekunder Transportasi Jarak Jauh Telur Ayam Ras dengan Metode Quality Function Deployment (Studi Kasus di PT Sugiarto Farm. Jurnal Teknologi Pertanian 17(3):177-186

Wicaksono, A,W. 2013. Penerapan Metode QFD (Qualityfunction Deployment) Padarencana Pengembangan Sekolah Di Smkn 2 Yogyakarta. Skripsi Universitas Negeri Yogyakarta. Yogyakarta

Wirya, I, 2008, Kemasan yang Menjual.

PT. Gramedia Pustaka Utama.

Jakarta 